\title{
O ESTÁGIO SUPERVISIONADO E A CONSTITUIÇÃO DA PROFISSIONALIDADE DOCENTE
}

\section{Maria de Fátima Garcia ${ }^{\mathbf{1}}$ \\ Universidade Federal do Rio Grande do Norte \\ Francisca Geny Lustosa ${ }^{2}$ Universidade Federal do Rio Grande do Norte}

\begin{abstract}
Resumo
Este artigo discute o estágio supervisionado sob três aspectos interrelacionados: a pesquisa colaborativa entendida como uma metodologia problematizadora de atuação utilizada no desenvolvimento das práticas do referido estágio; a imersão do estudante em sua futura profissionalidade docente; e a escola, território de tensões e transformações, lugar de (des)territorialização dos estágios e das práticas profissionais. Os dados produzidos remetem-se ao segundo semestre/2010 tendo como empiria relatórios de estágio dos estudantes do curso de Pedagogia do Centro de Ensino Superior do Seridó/UFRN, Caicó/RN. São aportes para as teorizações relacionadas à pesquisa colaborativa, estágio e profissionalização autores como Pimenta e Lima (2004); Sacristán (1995); Garcia (2002); Lustosa (2009), em intercessão privilegiada com os teóricos Deleuze; Guattari (2008; 1996; 1995). Ao final da investigação pode-se afirmar que a experiência do estágio, com base na problematização da escola, na ação-colaboração, e na multiplicidade de vivências, compõe uma miríade rizomática traduzida na constituição da profissionalidade docente.
\end{abstract}

Palavras-chave: Estágio;

Profissionalidade; Pesquisa Colaborativa. 


\title{
SUPERVISED STAGE AND DOCENT PROFESSIONALITY CONSTITUTION
}

\begin{abstract}
This article discuss supervised stage under three interrelated issues: collaborative research understood like an acting problematizing methodology used during development of practices of referred stage; student's immersion on his future docent professionality; and school, territory of tensions and transformations, place of stage operacionalization. Data produced reffer to second semester of 2010, have like empirics Seridó's Superior Teaching Center/UFRN (colocar o nome da instituição em português) student stage reports. Theoreticizations related to collaborative research, stage and professionalization bring, among others, Garcia (2002); Pimenta e Lima (2004); Sacristán (1995); Lustosa (2009); philosophers Deleuze e Guattari (2008; 1996; 1995). like study intercessors. At the end of investigation, it can be concluded that stage experience like base in school problematization, in action-collaboration, and the multiplicity of experiences compounds rhizomatic myriad translated in docent professionality constitution.
\end{abstract}

Keywords: Stage; Professionality; Collaborative Research. 


\section{Introdução}

Este artigo discute o Estágio Supervisionado, aqui denominado de estágio por meio da pesquisa, balizado pelo Projeto Pedagógico do Curso de Pedagogia do Centro de Ensino Superior do Seridó (CERES), campus da Universidade Federal do Rio Grande do Norte (UFRN). A matriz curricular em relação aos Estágios Supervisionados (I, II, III e IV) se organiza sob a seguinte distribuição: Estágio I se propõe a aproximação do graduando com instituições de Educação Infantil (creches e pré-escolas); Estágio II, que se dedica ao exercício da docência, por vezes, também designada de "regência” em sala de aula, nesse nível de ensino; Estágio III, aproximação com escolas de Ensino Fundamental I, sucedido do Estágio IV, constituído da prática nas séries iniciais do Ensino Fundamental.

Em particular, a atividade de Estágio III (Ensino Fundamental), foco de atenção nesta escrita, oferecida no sexto semestre do curso, antecede a atividade curricular de docência propriamente dita (Estágio IV), orienta em sua ementa que se trabalhe tendo como base a análise da realidade do sistema de Ensino Fundamental a partir dos modelos de organização da instituição escolar: planejamento, execução, coordenação e avaliação de projetos e experiências educativas desse nível de ensino.

Assim, a reflexão encetada, desde a ementa, descortina o terreno profícuo de se implementar uma prática de Estágio problematizadora, desenvolvida por meio da metodologia da pesquisa, a qual mobilize os estudantes a compreender a escola enquanto lócus da profissão e da constituição da profissionalidade docente.

Guiadas por essa perspectiva, desenvolvemos, no segundo semestre de 2010, uma experiência que buscou a articulação com a pesquisa como fundamento formativo por excelência. Junto à discussão, justificamos também a pertinência metodológica da abordagem escolhida, por ser esta a que melhor se coaduna com as prementes necessidades de transformações da cultura organizacional da escola e da prática docente. A vantagem de tal metodologia é que ela pode constituir rico e significativo espaço de formação docente, em razão da possibilidade de reflexão-da-ação que pode

Olh@res, Guarulhos, v. 1, n1, p. 90-115, maio. 2013. 
ser propiciado aos sujeitos nela envolvidos. Efetivar a progressiva melhoria da qualidade das ações desenvolvidas em atividades de Estágio é um dos desafios atuais de formação de professores, frente aos paradigmas contemporâneos.

O quadro teórico-conceitual desse estudo contemplou quatro deslocamentos agrupados nas discussões sobre Estágio Supervisionado (PIMENTA; LIMA, 2004); as questões específicas da Docência (NÓVOA, 1992); a pesquisa como emergência da investigação-ação com vistas a se problematizar a escola e, com ela, contribuir de forma emancipadora (GARCIA, 2002; LUSTOSA, 2009), dentre outros; o quarto deslocamento, articulado aos anteriores, relaciona-se às bases filosóficas do estudo e advém de Deleuze e Guattari (1995), teóricos contemporâneos que nos oferecem a possibilidade de se compreender a experiência do Estágio preconizada pelos estudantes em sua multiplicidade de vivências, conexões, saberes, práticas, colaboração, ensino(s), aprendizagem(ns) e subjetividades que compõem a impressionante "miríade rizomática" traduzida na constituição profissional dos professores.

Com o objetivo de apresentar a configuração dada no âmbito da proposta desenvolvida, o trabalho em tela está focado, particularmente, na análise das possibilidades de implementação do Estágio, baseado na problematização como estratégia formativa, pautado na fomentação da reflexão-ação e na intervenção da realidade, em um referencial que viabilize aos alunos situações de aprendizagem efetivas e intencionalmente críticas.

Nessa pretensão geral, considerando a demanda de ampliação de debates e novos conhecimentos no campo dos Estágios Supervisionados e considerando, ainda, a relevância da temática, intencionamos ampliar a produção científica à luz da discussão dos referenciais teóricos explicitados e da experiência realizada.

Para esse artigo, portanto, tomamos como fonte de análise os relatórios produzidos pelos discentes que cursaram a experiência do Estágio Supervisionado, realizados sob essa perspectiva.

Compreendemos que a fase dedicada ao Estágio é o momento em que o(a) estudante se (auto)avalia, avalia a formação recebida e se coloca no

Olh@res, Guarulhos, v. 1, n1, p. 90-115, maio. 2013. 
"entremezzo" de algo iniciado antes que ele(a) ali chegasse. Assim, este artigo, como afirma Deleuze (2008) diz coisas simples em nome próprio, fala por afectos (Deleuze, 1992) intensidades, experiências, experimentações, porém, com a compreensão de que,

Dizer algo em nome próprio é muito curioso, pois, não é em absoluto quando nos tomamos por um eu, por uma pessoa ou um sujeito que falamos em nosso nome. Ao contrário, um indivíduo adquire um verdadeiro nome próprio ao cabo do mais severo exercício de despersonalização, quando se abre às multiplicidades que o atravessam de ponta a ponta, às intensidades que o percorrem. (DELEUZE, 1992, p. 15)

A prática de Estágio Supervisionado atravessam-se tantas outras práticas, vozes, concepções, labores profissionais do corpo docente que fazem acontecer o curso de Pedagogia no cotidiano de formação. Na instituição em questão, várias colegas docentes se revezam na orientação do Estágio Supervisionado a cada semestre e, é com elas, que traçamos a grafia, o feitio do Estágio no CERES/DEDUC, o que confere, em certa medida, a este texto uma polifonia de vozes, e lhe dá colorido singular, mesmo que o recorte aqui apresentado se limite às experimentações ocorridas no segundo semestre de 2010.

A compreensão do Estágio Supervisionado aqui descrita traz os aportes da filosofia, porque é nela que encontramos subsídios para sua problematização que, por sua vez, nos conduz à metodologia da pesquisa onde subjazem as práticas de Estágio com a qual dialogamos ao longo deste estudo, sob a forma de exercícios de pensamento (GALLO, 2008), posto que se processa nos encontros ao longo deste texto: com os autores e teóricos aqui enunciados, com os relatórios de Estágio, com os alunos estagiários durante o ano de 2010, com as análises que suscitaram a produção dos dados e, no devir para além desta escrita, com os leitores deste artigo.

Dessa forma, buscamos realizar conexões, que compreendemos como os 'nós' que possibilitam que "qualquer ponto de um Rizoma pode ser conectado a outro e deve sê-lo" (DELEUZE; GUATTARI, 1996, p. 15), sendo que 'Rizoma', metáfora emprestada da botânica, significa caule radiciforme que cresce na horizontalidade estendendo-se e produzindo conexões, bulbos, linhas de articulação (ou segmentaridades), portanto,

Olh@res, Guarulhos, v. 1, n1, p. 90-115, maio. 2013. 
novas ramificações ${ }^{1}$. Assumir o Estágio supervisionado a partir da imagem do Rizoma, em sua horizontalidade, nos afasta da imagem-árvore unidirecional e hierárquica nos aspectos relacionados às práticas pedagógicas ditatoriais, dos diálogos consensuais, do poder dominante e de todos os 'centrismos' a saber: a visão adultocêntrica em relação à criança; os discursos falocêntricos em relação às questões de gênero, e etnocêntricos em relação às diversas etnias e multidiversidades presentes na escola; O rizoma nos abre à vivência das multiplicidades, conceito também deleuziano por nos possibilitar os entrelaçamentos, as articulações, as singularidades que se coletivizam da mesma forma que o coletivo se singulariza. $\mathrm{Ou}$, como afirma Gallo (2008, p. 69), “num rizoma [...] não há sujeitos, não há objetos, não há ações centradas em um ou outro; há projetos, acontecimentos [...] todo projeto é coletivo. Todo valor é coletivo. Todo fracasso também”. O rizoma não comporta a disciplinarização, mas se abre à criação, portanto, à invenção e, os conceitos são produzidos à medida que as linhas se estendem e se conectam. Por isso, pode-se ver neste texto teorias e práticas articuladas e problematizadas.

Destas problematizações, multiplicidades em devir (Deleuze e Guattari, 1995) inventa-se o novo, como por exemplo, as palestras aos estudantes e suas famílias quando, mais adiante, se problematiza a sexualidade na escola, o Bullying, a organização da gestão e suas implicações no processo de ensino e aprendizagem, a inclusão digital e outras tantas temáticas não recortadas à ilustração nos breves meandros desse artigo.

Sob a proposta desenvolvida esperamos formar o professor militante, que segundo Gallo (2008), é aquele que se constitui vetor de superação, que não age isoladamente, mas, sempre em ação coletiva, numa luta cotidiana de produção de possibilidades seja em sala de aula, nas relações com seus colegas professores, no ambiente social e, ainda na luta sindical. Professores militantes produzem educação, política, cultura e superações.

Ver-se-á durante o decorrer desta escritura que, parafraseando Gallo (2008) também tomamos de empréstimo conceitos deleuzianos para exercitar o

\footnotetext{
${ }^{1}$ No reino vegetal alguns exemplos de caules radiciformes conhecidos são as samambaias, as gramíneas, as orquídeas dentre outros.
}

Olh@res, Guarulhos, v. 1, n1, p. 90-115, maio. 2013. 
pensamento, e assim, produzimos deslocamentos de uma base filosófica para o campo da educação, desterritoriolizando conceitos da obra de Deleuze e Guattari para reterritorializá-los no campo do Estágio Supervisionado. Dessa forma, tais conceitos passaram a ser dispositivos que propiciam abertura de possibilidades de diálogo problematizador e novas criações entre os intercessores (Delleuze, 1995) escola-universidadeestagiários.

Feitas essas considerações, passamos a apresentar a estrutura e o conteúdo específico dos resultados do trabalho produzido, sobretudo, no sentido de fazer um "convite" à sua leitura. O texto transcorrerá a respeito da profissão docente no que se refere ao aspecto conceitual do termo profissionalidade. Ao trabalhar com tal conceitualização, como consequência, evidenciam-se dimensões tais como, a da reflexão sobre o que se entende por prática, das práticas aninhadas e do trabalho do professor. Antecipamos que ao longo da explanação que se tece nas seções deste texto, reunimos elementos que trataremos como aspectos da multiplicidade que se fazem presentes na elaboração da profissionalidade docente.

Profissionalização docente e a perspectiva de construção de saberes e de novas práticas: dimensões que se articulam

Não podemos avançar em investigações sobre a prática dos professores e a tarefa de ensinar, sem enveredar pelo conhecimento das dimensões que implicam a constituição da docência. Os saberes dos professores não se produzem de forma isolada. Eles são articulados com a pessoa do professor, sua história de vida, de formação e das experiências profissionais vivenciadas, além das intenções e interações específicas estabelecidas com os alunos e com os demais componentes da escola.

Tais características fazem com que o saber da docência seja percebido como de caráter eminentemente social e relacional (TARDIF, 2002). O saber dos professores como um saber social advém, portanto, do fato de ele ocorrer em uma realidade social materializada por uma formação, programas, práticas coletivas, disciplinas escolares, ou seja, de uma pedagogia institu-

Olh@res, Guarulhos, v. 1, n1, p. 90-115, maio. 2013. 
cionalizada e, ainda, pelo fato de serem também, ao mesmo tempo, imantados na subjetividade de quem os realiza.

De acordo com Sacristán (1995), o conceito de profissionalidade está em constante transformação e deve ser pensado em relação ao momento histórico e social concreto que o conhecimento escolar quer legitimar, portanto, há que ser contextualizado. $\mathrm{O}$ autor apresenta sua conceitualização acerca da questão ao dizer que: "Entendemos por profissionalidade a afirmação do que é específico na ação docente, isto é, o conjunto de comportamentos, conhecimentos, destrezas, atitudes e valores que constituem a especificidade de ser professor" (SACRISTÁN, 1995, p. 65).

Também é importante lembrar que a profissão docente se realiza no coletivo, por um grupo definido, com características e saberes específicos, inseparáveis dos que a executam. Esse saber não é uma produção encerrada em si mesma e por si mesma, pois depende dos contextos de trabalho subordinado aos mecanismos sociais, forças sociais interiores e exteriores à escola e apresentam uma diversidade e um pluralismo que dimensionam sua complexidade.

A discussão sobre os saberes da docência nos descortina sua pluralidade e multiplicidade de determinantes, apresentando-nos fontes diversas de saberes que se articulam. Esse fato nos faz questionar a importância da natureza de cada uma dessas fontes de saberes: haverá uma hierarquização ${ }^{2}$ quanto à natureza e à importância de cada uma dessas fontes promotoras desses distintos saberes?

Em torno da profissão docente socialmente se estabelecem expectativas, crenças, aspirações, exigências (SACRISTÁN, 1995). É ela também uma profissão que mantém estreito relacionamento com as famílias dos estudantes que depositam suas expectativas em relação ao futuro dos filhos, pautadas na formação oferecida pelos professores, todavia, como a sociedade muda constantemente, mudam-se também os referenciais de trabalho, e as obrigações de resposta às demandas tornam-se cada vez mais

\footnotetext{
${ }^{2}$ Quanto à hierarquização no campo dos saberes, Tardif (2002) argumenta que os professores não atribuem a mesma importância à natureza dos saberes e tendem a hierarquizá-los em função de sua utilidade prática, na aplicabilidade imediata que fazem no ensino.
}

Olh@res, Guarulhos, v. 1, n1, p. 90-115, maio. 2013. 
diversificadas, complexas e até mesmo confusas: afinal, como responder a questões que remetem ao futuro, quando este se encontra em permanente elaboração no momento presente?

\section{O que se caracteriza como prática educativa: dimensões (in)visíveis}

A feitura de uma epistemologia da prática educativa perpassa a priori pelo diálogo entre diversas concepções teóricas e múltiplas abordagens conceituais, bem como pela apresentação prospectiva de procedimentos, metodologias, objetivos ordenados na ação com e para determinados fins.

$\mathrm{Na}$ busca de precisar uma reflexão sobre a categoria analítica prática, deparamo-nos com uma profusão de termos e expressões que buscam uma conceitualização (inúmeros substantivos e substantivações, derivações e adjetivações).

A gama terminológica em torno da ideia de prática ${ }^{3}$, com o prévio reconhecimento de aproximações sinonímias, delineia em tons avivados na arquitetura do conceito: um conjunto de diferenciações que carecem de esclarecimentos mais precisos e sofisticados, organizados em torno de uma explicitação da própria gênese teórico-conceitual dos termos.

Como argumenta Zaballa (1998, p. 16), a prática precisa ser pensada "como algo fluido, fugidio, difícil de limitar com coordenadas simples e, além do mais, complexa, já que nela se expressam múltiplos fatores, ideias, valores, hábitos pedagógicos etc.” Isso, portanto, torna complexa a enumeração dos fatores e variáveis que a configuram. Prática esta, entendida segundo Sacristán (1995), como uma cadeia de inter-relações que compõem o sistema educativo. As discussões do referido autor favorecem uma visão crítica sobre as práticas educativas, considerando o macrossistema no qual estão inseridas.

\footnotetext{
${ }^{3}$ Essas expressões ou terminologias são usadas comumente para se referirem ao mesmo fenômeno, a exemplo, prática(s) educativa(s), atividade de caráter pedagógico, processo educativo, fazer pedagógico, ação pedagógica, docência, ação docente, ato educativo, prática escolar, trabalho pedagógico, prática pedagógica reflexiva e prática pedagógica crítico-reflexiva, entre outras.
}

Olh@ res, Guarulhos, v. 1, n1, p. 90-115, maio. 2013. 
No que concerne à constituição das práticas educativas, ainda segundo Zaballa (1998), podemos identificar elementos originados de fonte sociológica ou socioantropológica (concepção ideológica da resposta à pergunta de para quê ensinar, que incorpora a função social do ensino), a dimensão epistemológica (a função do saber e dos conhecimentos); a dimensão da didática (como ensinar e os critérios do ensino) e a dimensão psicológica (concepções sobre os processos de ensino e de aprendizagem). Assim, as finalidades, propósitos, objetivos gerais ou intenções educacionais constituem o ponto de partida primordial que determina, justifica e dá sentido à intervenção pedagógica realizada pelos professores.

Entretanto, para além da ação escolar o entendimento acerca do que seja a prática se alarga sem que se distancie da escola, pelo contrário, a esta se articula, inter-relaciona-se. Sacristán (1995) denomina de sistema de práticas aninhadas, posto que contém aspectos antropológicos, institucionais, educativos, além das práticas concorrentes ${ }^{4}$.

À medida que se adentra na compreensão da profissionalidade docente se percebe inúmeras conexões que se estabelecem e que desafiam os cursos de formação de professores, no intuito de oferecer aos estudantes possibilidades de vivenciarem, objetiva e subjetivamente, situações que os preparem para se inserir na profissão. Cada linha de segmentaridade, cujo entendimento nos remete à Deleuze e Guattari (1996), alcança e enlaça outra:

Somos segmentarizados por todos os lados e em todas as direções. O homem é um animal segmentário. A segmentaridade pertence a todos os estratos que nos compõem. Habitar, circular, trabalhar, brincar: o vivido é segmentarizado espacial e socialmente. Somos segmentados binariamente, a partir de grandes oposições duais: as classes sociais, mas também os homens e as mulheres [...]; circularmente, em círculos cada vez mais vastos, em discos ou coroas cada vez mais amplos [...] minhas ocupações, as ocupações do meu bairro, de minha cidade, de meu país, do

\footnotetext{
${ }^{4}$ Para o autor citado "a) Existe uma prática educativa e de ensino, em sentido antropológico, anterior e paralela à escolaridade própria de uma determinada sociedade e cultura. b) Nesse ambiente cultural, desenvolvem-se as práticas escolares institucionais, entre as quais podemos distinguir: - práticas relacionadas com o funcionamento do sistema escolar, configuradas pelo funcionamento do que deriva de sua própria estrutura;- práticas de índole organizativa, assentes nas utilizações próprias da organização específica das escolas; - práticas didáticas e educativas interiores à sala de aula, que é o contexto imediato da atividade pedagógica, onde tem lugar a maior parte da atividade de professores e alunos. c) Além disso, fora do sistema educativo, realizam-se atividades práticas que, não sendo estritamente pedagógicas, podemos considerar concorrentes das atividades escolares (1995, p. 69). Essa estruturação apresentada interessa, em particular, a esta investigação, notadamente, pela compreensão de que não se pode apreender as práticas didáticas e educativas sem nenhuma referência às outras práticas institucionais e as organizativas que lhe servem de enquadramento e suporte.
}

Olh@res, Guarulhos, v. 1, n1, p. 90-115, maio. 2013. 
mundo; [...] linearmente, numa linha reta e em linhas retas onde cada segmento representa um episódio ou um "processo": mal acabamos um processo e já estamos começando outro [...]. Mas sempre estas figuras de segmentaridade, a binária, a circular e a linear são tomadas umas nas outras, transformandose de acordo com o ponto de vista (p. 84).

Tomada a prática como uma das dimensões da profissionalidade em seus aspectos segmentares múltiplos, imediatamente aciona-se outra linha que se articula nesta teia de malhas e meandros tão sutis no emaranhado da profissionalização, a qual diz respeito ao trabalho dos professores - ao que é considerado importante em termos do contexto histórico, local, localizado ou global. Como exemplo, podemos enumerar: as nuances curriculares inscritas em teorizações advindas de campos epistemológicos, por vezes, concorrentes na educação (sociológica, antropológica, filosófica, psicológica) originadas em âmbito nacional ou internacional; a exigência maior ou menor de formação verticalizada (cursos de pós-graduação) ou horizontalizada (cursos de formação continuada); a excessiva burocratização que rouba o tempo pedagógico; a crescente proletarização a que a categoria é permanentemente submetida tanto em termos salariais quanto em termos de pobreza das condições de trabalho (escolas e salas de aula pauperizadas, para citar apenas essas dentre muitas).

No caso específico dos profissionais da educação, é preciso refletir sobre as circunstâncias atuais em que a prática pedagógica se efetiva, sendo necessário, associado a isso, também refletir sobre a história da profissionalização docente e se insuflar criticamente sobre as atuais condições de constituição e de realização da ação pedagógica nas escolas públicas. De acordo com Nóvoa (1992), há uma grande distância entre a visão idealizada da profissão docente como mister de valoração social e a realidade onde ela se efetiva, ou seja, a situação concreta do ensino, aspecto no qual está situado o centro de uma das crises na profissão com a qual convivemos hoje.

Se a dimensão da categoria trabalho aqui é entendida como uma das muitas dimensões da profissionalização, fica evidente que esta comporta em si tantos outros aspectos múltiplos que se articulam e não podem ser ignorados.

Olh@res, Guarulhos, v. 1, n1, p. 90-115, maio. 2013. 
Com efeito, pelo que foi enunciado até aqui, cabe a indagação: 'que metodologia utilizar no Estágio Supervisionado de forma a que o(a) estudante se perceba como parte do coletivo profissional da profissão escolhida? Como possibilitar que os futuros pedagogos compreendam que, em breve, atuarão em um contexto profissional cuja característica reside justamente na multiplicidade?'

Defendemos que a problematização crítica da realidade educativa se apresenta como uma das vias possíveis para tal empreitada, subsidiada pela metodologia da pesquisa colaborativa. E por que a pesquisa colaborativa? Porque esta traz em si a possiblidade da participação coletiva daqueles que estão na escola (alunos, professores, gestores, pais); a certeza da transformação, mesmo sabendo-se que tal certeza anuncia-se revestida de provisoriedade sob a forma de ações concretas que contribuam com a escola; a emergência de novos agenciamentos, propiciados pelos acontecimentos que criam sempre novas linhas, e linhas de fuga no sentido deleuziano do conceito. A seguir, explicitamos as articulações entre Estágio Supervisionado por meio da pesquisa e suas inter-relações com a aprendizagem da docência.

Estágio Supervisionado por meio da pesquisa: a escola, suas interrelações e tensões como espaço de pesquisa e de aprendizagem do "ser docente"

Articular Estágio e pesquisa como formas de aprendizagem possibilita ao estagiário melhor compreender a instituição escolar como o território onde será exercida a sua profissionalidade, apesar de considerarmos que outros espaços - não escolares - cada vez mais têm se aberto ao exercício da profissão do(a) pedagogo(a). É também compreendê-lo situado e permeado em conexões, multiplicidades, rizomas e deslocamentos.

Temos afirmado que o

Estágio supervisionado caracteriza-se como o momento, previsto na estrutura curricular e possibilitado pelo Projeto Pedagógico do Curso, em que o estudante encontra-se consigo mesmo e aprofunda o nível de consciência em relação à profissão escolhida; Revê e reavê conhecimentos, reencontra postulados teóricos, adota alguns rejeita outros, mas, sobretudo, atenta para o compromisso e a responsa-

Olh@ res, Guarulhos, v. 1, n1, p. 90-115, maio. 2013. 
bilidade de seus atos profissionais ante à sociedade, à vida de outras pessoas (...). Tal consciência recai sobre [pensar] a formação de seus futuros alunos e o futuro educacional de sua nação, porquanto percebe-se como alguém que contribuirá, efetivamente, para a formação de mentes e mentalidades (GARCIA, 2012, p. 239).

O Estágio reúne em diálogo, docentes da academia e os atores da escola, gestores, funcionários, alunos, pais, práticas, saberes, problemas e soluções, em paripasso, cotidiano e diversidade, tempo e espaço, tensões e relações de poder, constituintes de uma cartografia propícia para que os estudantes reflitam acerca de sua profissionalidade.

A despeito disso, assinalamos como sendo justamente aí que reside o aspecto múltiplo que caracteriza a miríade rizomática: a universidade e suas pesquisas articulam-se à escola, ao conhecimento dos estudantes, que (também) são pesquisadores, às práticas dos estudantes durante o Estágio que, por sua vez, se misturam à prática dos professores da escola, os quais aprendem com os estudantes - e estes aprendem com os professores da escola.

Autores como Nóvoa (1992), dentre outros, auxiliam-nos a pensar a formação para a ação da docência, referendados no conceito de reflexividade. Estudos como os de Schön (1992) evidenciam que um fator responsável pelo não desenvolvimento a contento de ações mais inovadoras dos profissionais em geral é certa impossibilidade que se apresenta à prática profissional - a dificuldade de instaurar a problematização na ação. Esse fato dificulta a transformação do trabalho numa práxis reflexiva. Particularmente, surgem na contemporaneidade princípios da perspectiva atual de formação de professores articulada às ideias de profissionalização do ofício de professor e da prática reflexiva (PERRENOUD, 2000), de forma que a perspectiva do Estágio pela pesquisa pode atender.

Não obstante, problematizar o contexto educativo, o espaço da escola, ambiente material de realização da ação docente, e tomá-la como referência para a identificação de inquietações de pesquisa, requer compreendê-la inserida num cenário intenso de embates socioculturais e político-ideológi-

Olh@res, Guarulhos, v. 1, n1, p. 90-115, maio. 2013. 
cos, em que se fabricam demandas e exigências a serem atendidas ${ }^{5}$.

Assim, é notória a reflexão sobre a constituição da profissionalidade docente na contemporaneidade, (re)visitar concepções e práticas no campo da Formação de Professores, notadamente, em face das demandas de um perfil profissional contemporâneo, trazendo como condição sine qua non aos docentes a necessidade de transformação e atualização dos referenciais das práticas pedagógicas efetivadas no contexto educacional.

Cumpre registrar, ainda, que uma formação crítica e consistente do educador requer a tomada de consciência da docência no panorama atual dos sistemas públicos de ensino, levando em conta as realidades específicas de seu trabalho cotidiano, que colaboram para anunciar as diversas naturezas de tensões em que reside a atuação do ser docente, em parte, acirrada pelas condições objetivas concretas em que a ação acontece.

Estudos anteriores sobre o espaço da escola (LUSTOSA, 2009; LUSTOSA e SANTOS, 2010), evidenciam ainda que, coexistem atitudes de resistência à mudança, exacerbada burocratização do sistema de ensino e hierarquização, além de formas cristalizadas de autoritarismo nas escolas, elementos que abalam e fragilizam a construção/fortalecimento da profissionalidade dos professores e que prescindem ser tematizadas/problematizadas na e pela Formação.

Advinda desse cenário de demandas formativas é que se requer metodologias de que melhor propiciem a constituição do ensinar e do aprender. É o que discutiremos a seguir, ao abordar a concepção de metodologia de ensino pela pesquisa.

\footnotetext{
${ }^{5}$ Por essa razão, emerge a necessidade de pensar sobre o construto de um modelo explicativo mais amplo, ou seja, não limitado apenas ao campo didático-pedagógico, e sim, inserido no âmbito de tal estruturação societária, que possa abranger os aspectos mais críticos que envolvem uma análise sobre os aspectos sociais, culturais, éticos e políticos como também constituintes da formação para a prática pedagógica. Há de se considerar, ainda, um cabedal de conhecimentos mais atuais (fundamentados inclusive nos avanços das ciências, da Psicologia e da própria Pedagogia), necessários de serem acessados para a consolidação de uma intervenção educativa de qualidade.
}

Olh@res, Guarulhos, v. 1, n1, p. 90-115, maio. 2013. 


\section{Concepção de pesquisa como metodologia de ensino e aprendizagem}

Antes de iniciar esta seção convém elucidar que pesquisa neste contexto é vista, por um lado - como uma metodologia podendo ser de ensino, quiçás, de aprendizagem no sentido defendido por Garcia (2002), cuja tônica é a problematização de aspectos voltados à educação, à escola, às aprendizagens, à alguma temática em especial do currículo, ou, dependendo do nível, se educação básica ou superior, às questões das políticas educacionais, da formação (ou quaisquer outros), conforme a realidade problematizada. E, por outro lado, de educação pela pesquisa tal como a referenciada em Demo (1998), cuja ênfase recai no que o autor denomina de “questionamento reconstrutivo", base para a (re)elaboração própria (daquele que pesquisa), que por sua vez aciona o comprometimento técnico e político, com a compreensão de que ambos são indissociáveis.

A pesquisa sob a ótica de metodologia de ensino e de aprendizagem exige, porém que se apreendam os mesmos saberes relacionados à prática da pesquisa caracterizada como acadêmica, mais precisamente de abordagem qualitativa, utilizando-se os procedimentos da pesquisa-ação, participante ou colaborativa. Sua aplicação requer a enunciação de um problema, a explicitação de objetivos, dos procedimentos metodológicos, dos fundamentos teóricos, de análise argumentativa e considerações a partir do que foi estudado/pesquisado. Sob esta metodologia os estudantes aprendem e pesquisam; os professores orientam a pesquisa, por sua vez, ensinam e aprendem. Cria-se o que Garcia (2002), ao estudar como professores e alunos podem juntos se aventurar no mundo da pesquisa, denominou de Comunidade Educacional. Esclarecemos que não estamos aqui tratando de metodologia de projetos, posto que, os estudantes-pesquisadores (no caso, estudantes em atividade de Estágio Supervisionado) adquirem desde o início as bases de como a ciência se processa, suas regras e rigor, no compromisso com a socialização de seus conhecimentos produzidos. Passam a entender que quem pesquisa adquire voz própria e autoria.

Essa forma de abordar metodologicamente o ensino e a aprendizagem poderá ser trabalhada em qualquer nível de ensino, tendo-se apenas o cui-

Olh@res, Guarulhos, v. 1, n1, p. 90-115, maio. 2013. 
dado com a gradação do aprofundamento ${ }^{6}$. Ensino, aprendizagem e pesquisa não podem mais caminhar separados, pois a pesquisa desperta a curiosidade, desafia intelectualmente o aluno; provoca conflito sociocognitivo, etc. A pesquisa, por partir da indagação, portanto, da curiosidade epistêmica abrese para o novo, desperta o ato criativo, possibilita a elaboração própria, mobiliza o corpo e constitui mentalidades.

A atuação problematizadora possibilita uma visão horizontalizada do sistema de ensino, da escola e de suas práticas, na medida em que se adotem aportes teórico-metodológicos que permitam entender como se constitui essa horizontalidade, à maneira de linhas segmentares que se conectam, articulam e se cruzam no cotidiano escolar construindo vetores de força. (DELEUZE; GUATTARI, 1995)

As problemáticas também evidenciam uma concepção de Estágio e, por certo, de pesquisa: a de que o olhar da universidade deve estar voltado para a parceria, para a contribuição, para a transformação da escola. É fato que, durante certo tempo, o Estágio e as pesquisas acadêmicas eram desqualificadores dos saberes escolares, daí a recusa de muitas escolas em não receber alunos estagiários. O Estágio por meio da pesquisa, ao contrário, estabelece parceria de colaboração, produz novos intercessores, reflexão partilhada entre os que fazem a escola em seu cotidiano e os estudantes da universidade que lá chegam, mas também requer que os estagiários dominem as metodologias da pesquisa e os devidos procedimentos metodológicos.

No sentido de discutirmos tais problematizações, apresentamos cinco temáticas de Estágio trabalhadas sob a perspectiva enunciada, selecionadas de um universo de vinte Relatórios de Estágio Supervisionado e, para uma

\footnotetext{
${ }^{6}$ Por exemplo, uma temática de meio ambiente problematizada por um aluno de sétimo ano de ensino fundamental I, não poderia ter o mesmo aprofundamento que o de um estudante de ensino superior de Pedagogia, mas ambos poderão se utilizar das mesmas orientações procedimentais concernentes a esses tipos de pesquisa. Nos níveis fundamentais e médio de ensino esta forma de ensinar e aprender traz o benefício de se problematizar o currículo ao mesmo tempo em que desperta nas crianças e adolescentes o gosto pela Ciência, o prazer da descoberta, e a importância de se entender desde cedo que a produção de conhecimentos se caracteriza por ser de natureza social. Ações transformadoras, localizadas, advindas de pesquisas feitas por alunos de ensino fundamental e médio já são realidade em escolas onde se desenvolve o ensino por meio desse tipo de metodologia de ensino e como exemplo citamos as experiências bem sucedidas envolvendo escolas de Campinas, estado de São Paulo, registradas em GARCIA (2002), DAMIN (2004), dentre outros.
}

Olh@res, Guarulhos, v. 1, n1, p. 90-115, maio. 2013. 
visualização de caráter panorâmico dispusemos os dados mais gerais, em tabelas, objetivando demonstrar as diversas linhas que se entrecruzam: a problemática definida, a problematização, objetivada por uma questão direcionadora, os autores referenciados para o estudo, e a abordagem metodológica utilizada no Estágio por meio da pesquisa. Em sequência, são extraídos alguns trechos dos relatórios, entendidos aqui como vozes e autoria dos estagiários.

Tabela no 1 - Temáticas e problemáticas

\begin{tabular}{|c|c|}
\hline Temáticas & Problemáticas \\
\hline $\begin{array}{l}\text { 1. Organização da gestão e } \\
\text { suas implicações no } \\
\text { processo de ensino e } \\
\text { aprendizagem } \\
\text { instituição escolar }\end{array}$ & $\begin{array}{l}\text { 1- É possível organizar uma gestão que atue diretamente no processo de ensino e } \\
\text { aprendizagem dos alunos e nas relações entre os agentes escolares? (relações } \\
\text { interpessoais, os processos de ensino e aprendizagem) }\end{array}$ \\
\hline $\begin{array}{l}\text { 2. Inclusão digital na } \\
\text { Escola }\end{array}$ & $\begin{array}{l}\text { 2- O que a escola tem feito para promover a inclusão digital dos alunos, } \\
\text { especificamente quanto ao uso ético e legal da Internet como auxílio à pesquisa } \\
\text { escolar? }\end{array}$ \\
\hline $\begin{array}{l}\text { 3. Bullying Escolar: Um } \\
\text { olhar sobre a realidade da } \\
\text { Escola Estadual Maria } \\
\text { Terceira }\end{array}$ & $\begin{array}{l}\text { 3- Quais os fatores que favorecem o desenvolvimento do bullying escolar? Quais as } \\
\text { principais consequências que esse comportamento pode causar às vítimas? Os } \\
\text { profissionais da educação sabem acerca da importância de se entender sobre o } \\
\text { assunto e estão preparados para enfrentar essa problemática? }\end{array}$ \\
\hline $\begin{array}{l}\text { 4. Inclusão/Participação da } \\
\text { família e seus benefícios } \\
\text { para o processo educativo }\end{array}$ & $\begin{array}{l}\text { 4- Até que ponto a participação ativa dos pais favorece o desempenho escolar dos } \\
\text { educandos? }\end{array}$ \\
\hline $\begin{array}{l}\text { 5. Sexualidade na Escola: } \\
\text { além do estudo do corpo }\end{array}$ & $\begin{array}{l}\text { 5- "De que maneira a sexualidade perpassa o espaço escolar, penetra na Educação de } \\
\text { forma global e específica, disseminando "micropoderes" sobre os corpos? E quais as } \\
\text { implicações desses "micropoderes?"sobre a identidade de seus integrantes, } \\
\text { primordialmente os alunos [enquanto sujeitos em formação inicial]?; De que forma } \\
\text { professores e demais agentes educativos comportam-se em relação à sexualidade de } \\
\text { seus alunos: suas ações são repletas ou perpassadas de preconceitos? Como são } \\
\text { tratados os comportamentos sexuais expostos pelos alunos dentro do ambiente } \\
\text { escolar, primordialmente no chão da sala de aula? Quais as intervenções (verbais e } \\
\text { físicas) que professores e agentes educativos adotam durante as brincadeiras das } \\
\text { crianças, há um direcionamento para aquilo que [é considerado] feminino e o que é } \\
\text { masculino?; Ainda assim, é permitido que os alunos escolham livremente as } \\
\text { brincadeiras e os brinquedos que lhes despertam interesse? }\end{array}$ \\
\hline
\end{tabular}

Fonte: Relatórios de Estágio Supervisionado, 2010.2, CERES/DEDUC.

Olh@res, Guarulhos, v. 1, n1, p. 90-115, maio. 2013. 
Consecutivamente, explicitamos as principais perspectivas teóricometodológicas adotadas e fontes de literatura que constituíram o constructo teórico.

Tabela $\mathbf{n}^{\circ} 2$ - Metodologias utilizadas e literatura de base

\begin{tabular}{|l|}
\hline \multicolumn{1}{|c|}{ Metodologias empregadas/procedimentos metodológicos } \\
\hline 1. Temática da Organização da gestão e suas implicações no processo de ensino e aprendizagem na \\
instituição escolar - Pesquisa qualitativa/entrevistas semiestruturadas, com vistas a captar a visão dos \\
alunos sobre a escola lócus; \\
2. Inclusão digital na Escola - Pesquisa diagnóstica a fim de compreendermos a realidade do ambiente \\
escolar no que concerne a prática de inclusão digital realizada; Intervenção: oficina para os professores \\
sobre a problemática; \\
3. Bullying Escolar - Pesquisa de cunho qualitativo; palestras; oficinas; aplicação de questionários e \\
observação da realidade no cotidiano escolar; \\
4. Inclusão/Participação da família e seus benefícios para o processo educativo - Pesquisa qualitativa: \\
a) Observação prévia do ambiente escolar; b) Análise de (algumas) conversas informais com professoras \\
e alunos sobre essa temática; c) Aprofundamento no estudo acerca da temática em bibliografias \\
específicas; d) Utilização de dados quantitativos e produção de gráficos; e) Diálogo com o corpo docente \\
da escola com vistas à coleta de dados e maior segurança nas tomadas de decisões; Oficina para os pais, \\
alunos e equipe pedagógica; \\
5. Sexualidade na Escola - Pesquisa qualitativa; observação na informalidade das conversas na escola; \\
Intervenção: palestra na escola sobre sexualidade, proferida por um professor do curso de História. \\
\hline Literatura em que se fundamentaram os estudos (Citadas em Relatórios de Estágio Supervisionado/ \\
DEDUC-CERES, 2010). \\
Libâneo (2009); Lück (2000); Freire (1996); Pimenta e Lima (2004); Zabala (1998); Silva (2005); \\
Pimenta (1987); Brasil (2001); Silva (2010); Fante (2005); Godoy (1995); Constantini (2004); Canário \\
(2006); Melo (2010); Paro (2000); Lück (1981); Vieira (2002); Pimenta (2001); Foucault (1988) Stuart \\
Hall; Louro (2001); Brasil, Constituição Federal (1988). LDBEN 9394/96; Parecer 21: CNE 2001); \\
BRASIL (1988-PCNs); Silva (2008); dentre outros.
\end{tabular}

Fonte: Relatórios de Estágio Supervisionado, 2010.2, CERES/DEDUC.

Na Tabela 1, referentes às problemáticas podemos observar a diversidade de indagações de pesquisa e, na Tabela $\mathrm{n}^{\circ} 2$ as Metodologias Empregadas/Procedimentos metodológicos juntamente aos autores estudados, todos, elencados independentemente da sugestão das professoras orientadoras do Estágio, mas buscados por iniciativa e autonomia intelectual dos estudantes, com vistas a dar conta da situação investigada.

Chamamos a atenção para as preocupações que as estudantes evidenciavam em relação ao desejo de compreender aspectos voltados para: gestão da escola, em sua relação com o ensino e a aprendizagem; os aspectos éticos em relação ao uso das novas tecnologias na educação; à ocorrência do Bullying nos espaços escolares, buscando primeiramente entender o significado e as consequências desse tipo de violência por meio da literatura e, depois, questionando o que os agentes escolares (professores, gestores,

Olh@ res, Guarulhos, v. 1, n1, p. 90-115, maio. 2013. 
funcionários em geral, alunos e pais) sabem a respeito e o que fazem para solucionar o problema; à relação da família com a escola e as implicações no que se refere ao desempenho escolar das crianças; e, à questão da sexualidade para além do estudo bio-fisiológico do corpo, bem como a compreensão das formas com que esta temática tem sido abordada na escola.

Cada uma dessas temáticas em sua problematização exigia que fossem buscadas outras leituras, ampliando-se novamente as linhas de alcance da formação, específicas do objeto estudado, muitas vezes, literaturas não contempladas durante a formação, até porque o fenômeno em estudo revestia-se de tamanha atualidade, como, por exemplo, o bullying escolar: quando o estagiário, autora do relatório, ingressou na universidade, no ano de 2008, praticamente esse assunto começava a despertar a atenção dos pesquisadores no Brasil. Imaginemos o desafio que esse estudo representou para uma estudante de graduação em apoderar-se desse objeto de investigação, em apenas um semestre de Estágio, quando a literatura disponível ainda era muito incipiente! (sem considerar que o Estágio foi desenvolvido em um município do interior do estado e a livraria mais próxima da cidade encontra-se a $280 \mathrm{~km}$ de distância, em Natal, capital do estado do Rio Grande do Norte)

A título de ilustração, fazemos referência à outra dupla de estagiários cuja problemática envolvia conhecer as metodologias de ensino e aprendizagem que perpassam pelo cotidiano das práticas que circulam na escola, e perceberam que para adquirir essa compreensão era necessário ter acesso ao projeto pedagógico da instituição e depois, aos próprios agentes escolares para então, planejar, em conjunto, uma contribuição à mesma. Aspectos relacionados à profissionalização docente vêm à tona durante o encontro de intervenção planejado pelos estagiários com esse intuito, como exposto a seguir.

Olh@ res, Guarulhos, v. 1, n1, p. 90-115, maio. 2013. 


\section{Quadro no 1 - Diagnóstico-reflexão-ação: o papel dos intercessores da escola e da academia}

De acordo com todas as informações obtidas, embasadas na realidade presenciada, sugerimos três ações na escola [...], a segunda foi o encontro com os agentes educativos de toda a escola, feito em clima de muita conversa e troca de conhecimentos, todos ficaram bastante à vontade no encontro, fizeram colocações e expressaram suas opiniões acerca da carreira docente, seus pontos positivos e negativos [...] e a terceira foi em sala de aula do $1^{\circ}$ e $2^{\circ}$ anos do Ensino Fundamental [...], foi realizado um dia de aula diferente, com procedimentos metodológicos diversificados, favorecendo a interdisciplinaridade e os temas transversais propostos no projeto [pedagógico do curso], trabalhando a valorização da leitura e da escrita, de maneira criativa. Como estratégia foi executada uma espécie de gincana, os alunos foram divididos em grupos e tiveram atividades para serem cumpridas. Depois deveriam se apresentar para toda a escola, de maneira dinâmica, como um verdadeiro espetáculo. Todos os alunos se empenharam e participaram, usaram figurino, maquiagem, foi trabalhado a interpretação de texto, mímicas, contação de histórias e piadas.

Fonte: Relatório de Estágio Supervisionado, 2010.2, CERES/DEDUC.

São perceptíveis pelo relato do aluno momentos distintos e interrelacionados que se definem como "Diagnóstico-reflexão-ação", bem como o papel dos intercessores da escola e da academia. Intercessor (DELEUZE, 1992) é mais que um simples termo ou expressão em Deleuze e Guattari, é um conceito que remete de si a outrem, que o ajuda a se exprimir, mas que também jamais se exprimiria sem este, posto que sempre se trabalha em vários, mesmo quando isso não se vê. Os intercessores aqui contribuem com os estudantes em seu entendimento acerca da escola, das práticas ali subjacentes, mas também em relação ao ofício de serem professores.

Outra dupla de estagiários, por exemplo, imbuídos em problematizar até que ponto a participação ativa dos pais favorece o desempenho escolar dos educandos, utilizou-se de procedimentos quantitativos, expressos por gráficos, para demonstrar o envolvimento das famílias na educação dos filhos, mas incluíram também os alunos, posto que se fazia importante compreender o que as crianças pensam dessa questão. Os resultados demonstraram que $94 \%$ acham muito importante a participação dos pais, $3 \%$ não a consideram importante e os demais 3\% não sabiam responder. Reforçam esse envolvimento ao afirmarem que $80 \%$ dos seus pais frequentam a escola e ainda, $83 \%$ disseram que os pais contribuem com as tarefas escolares.

Esta linha de segmentaridade, ao ser estendida aos pais, revelou que eles consideram importante a participação na vida dos filhos. Relevante esse deslocamento do olhar dos estagiários sobre os resultados obtidos na investigação, pois contradiz as afirmações recorrentes da escola de que os

Olh@ res, Guarulhos, v. 1, n1, p. 90-115, maio. 2013. 
pais não se preocupam, tampouco se envolvem com a educação dos filhos, deixando tudo a cargo da escola.

Apesar de não expresso, subliminarmente podemos interpretar que as crianças aprendem na família a importância, a preocupação e o envolvimento com sua formação, todavia a mesma investigação identifica uma lacuna quando se questiona a escola em relação ao que é oferecido por esta, para que a família realmente se envolva, se territorialize na escola e faça desta o seu lugar e ali se estabeleça como partícipe de uma verdadeira comunidade escolar. Vejamos o quadro a seguir com o relato analítico do estagiário sobre esse aspecto em particular.

\section{Quadro $n^{0} 2$ - Como a escola promove o envolvimento da família}

Sobre a existência de algum tipo de projeto de inclusão familiar, dos dez entrevistados [professores e equipe diretiva] apenas quatro afirmaram conhecer um projeto [da escola para as famílias] intitulado tempo de recomeçar, mas, quando questionados sobre o teor do projeto, apenas a supervisora explicou o seu funcionamento.

Fonte: Relatório de Estágio Supervisionado, 2010.2, CERES/DEDUC.

A análise tem significância para os processos de subjetivação no contexto escolar, porque vem confirmar que a escola não é simplesmente estática e reprodutora de ideologias, mas, sim, um campo de conflitos de constantes produções e reproduções, e que seus atores não são meros apropriadores do que nela circula, mas intensos produtores de novos discursos, ações e "dissidentes subjetivações".

Outro aspecto importante de assinalar é o fato de que por meio dos resultados presentes no relatório de Estágio dos estudantes constatamos que as práticas pedagógicas reinantes ainda trazem um ranço cartesianopositivista. No caso da sexualidade, temática abordada no interesse de uma das duplas de estagiários, a escola comumente delega ao estudo da disciplina Ciências, num enfoque voltado unicamente à reprodução humana, adicione-se aqui o componente religioso, que enxerga o ser humano cindido em corpo e mente, sendo a mente a guardiã do intelecto, e o corpo, principalmente os órgãos sexuais, relacionado à vergonha e ao pudor.

Ao eleger essa temática para pesquisa durante o Estágio os alunos aprofundaram o seu conhecimento a respeito do assunto, socializaram co-

Olh@res, Guarulhos, v. 1, n1, p. 90-115, maio. 2013. 
nhecimentos com as crianças e adultos da comunidade escolar, levaram um professor do curso de licenciatura em História para palestrar junto aos adolescentes sobre a temática.

Parece evidente que a profissionalidade docente, então, dessa forma, é apreendida pelos estagiários, no contorno dos "mapas em desenho", nas grafias das reflexões e intercessões que se delineiam por meio de suas pesquisas na escola. É o que percebemos a partir do depoimento do estagiário sobre a experiência vivenciada, a seguir no Quadro 3:

\section{Quadro n 3 - Constituição da profissionalidade docente}

"Esta experiência proporcionada pelo estágio amplia o significado da constituição de um profissional da área da educação, complementa a formação acadêmica e confere subsídios para uma atuação democrática e transformadora"

Fonte: Relatório de Estágio Supervisionado, 2010.2, CERES/DEDUC.

E, assim, no inter-relacionamento das múltiplas linhas que se cruzam novos rizomas se conectam, novos(as) pedagogos(as) vão nascendo e se juntando aos que já por aí estão: o segmento da universidade, que alcança o segmento da escola, enreda os estudantes da pedagogia em seus estágios, abarca as crianças e seus professores e gestores nas escolas públicas onde se materializam as práticas de estágio, seja em formatos circulares ou lineares. Suspendemos, por hora, esta conversação - parafraseando Deleuze - que se encontra atravessada por outros tantos intercessores, vozes, práticas, profissionalidades, mas nos encontramos todos nas articulações do cotidiano de nossos espaços docentes.

\section{Considerações Finais}

Temos consciência de que apenas elaboramos indicações inacabadas sobre caminhos possíveis para romper e transformar a organização do Estágio Supervisionado, aqui apresentado pela experimentação testemunhada de uma vivência ("corporeificação da palavra pelo exemplo").

Para finalizar, é preciso assumir que experiências de várias ordens aconteceram no Estágio Supervisionado por meio da pesquisa e que não

Olh@ res, Guarulhos, v. 1, n1, p. 90-115, maio. 2013. 
couberam neste ensaio. Mas, podemos afirmar que a consciência em relação à profissionalidade vivenciada a partir da problematização e práticas desenvolvidas no Estágio enredou-se numa multiplicidade rizomática que se constituía a cada problemática estudada. Os estagiários vivenciaram conflitos, rupturas, parcerias/resistências, partilhas, estudos, planejamentos de intervenções e sonhos de mudança.

No que concerne à metodologia de Estágio por meio da pesquisa, aqui relatada, constatamos que ela possibilitou aprofundamentos dos conhecimentos sobre temas diversos (uma multiplicidade de temáticas atualizadas), emergidas das necessidades reais da escola, problematizadas pelos estagiários, fato que amplia as linhas de alcance da formação, muitas vezes, não contempladas durante a graduação. Nessa circunstância formativa, abre-se espaço para novas informações, ascese do pensamento crítico, desmistificação de concepções e oportunidade de mudança do modelo tradicional clássico em que as práticas pedagógicas ainda são arraigadas.

Dentre os aspectos formativos destacamos a experimentação em situação real e a vivência dos ciclos investigatórios pelos quais passam normalmente estudos de empiria acadêmica dessa natureza, quais sejam: em um primeiro momento, a definição do problema e diagnóstico da realidade; num segundo, a busca de solução pela problematização; em terceiro, a aplicação de situações interventivas e quarto, a avaliação dos resultados da aplicação. Assim, interessados em um problema que emerge num dado contexto, orientados por uma preocupação compartilhada entre os sujeitos que nela atuam, desempenhando papeis distintos, os estagiários atestam a significação da aprendizagem ocorrida, que, segundo seus depoimentos, tiveram importância ímpar para suas formações, mas que representou contribuição de igual valor também para a escola.

Enfim, podemos acentuar que, como desdobramento dos estudos e vivências oportunizadas no Estágio implementado (tomando a escola e a própria experiência dos sujeitos como locus privilegiado da formação docente, apoiadas na reflexão-ação-reflexão sobre a ação), ocorre a expansão e novas linhas segmentares, que, no mínimo, abalam compreensões primeiras e/ou

Olh@res, Guarulhos, v. 1, n1, p. 90-115, maio. 2013. 
embrionárias que, por sua vez, possibilitam aos estudantes (re)leituras da profissionalidade no campo da pedagogia.

É pertinente assinalar, todavia que as conclusões mais importantes deste estudo estão de fato no percurso e não só no produto que dela se originou. Elas estão fortemente imbricadas na trajetória, na palavra-conceito "processo", uma vez que é na vivência dos fenômenos que a aprendizagem se faz carregada de significação.

Vivências como a que apresentamos aqui, constituída na decência, encharcada de esperança e intencionalidade (FREIRE, 1997), na busca de uma formação mais significativa, apesar de seus limites, nos impelem a acreditar que o estágio pela pesquisa pode realizar pela formação algo análogo ao que asseverou Freire, instaurar o "inédito viável”! 


\section{Referências Bibliográficas}

BOURDIEU, P. Escritos de educação. Petrópolis, RJ: Vozes, 1998.

CERES/DEDUC. Relatórios de Estágio Supervisionado. (Arquivos do CERES) Caicó: RN, 2010.

DAMIN, M. A. Olhares nômades sobre o aprendizado da modelagem matemática no “projeto Ciência na Escola”. Dissertação de mestrado. Campinas: UNICAMP. 2004.

DEMO, P. Educar pela pesquisa. Campinas. SP: Autores Associados. 1998.

DELEUZE, G.; GUATTARI, F. Mil Platôs: Capitalismo e Esquizofrenia V. 1 Rio de Janeiro: Ed 34. 1995.

DELEUZE, G.; GUATTARI, F. Mil Platôs: Capitalismo e Esquizofrenia V. 3 Rio de Janeiro: Ed 34. 1996.

DELEUZE, G.; Conversações. Rio de Janeiro: Ed 34. 1992.

FREIRE, P. Pedagogia da Esperança: um reencontro com a pedagogia do oprimido. 4. ed. Rio de Janeiro: Paz e Terra, 1997.

GARCIA, M.F. O Estágio Supervisionado como Campo de Desterritorialização da Teoria e da Prática de Ensino. In: SANT'ANA, C. C. de.; SANTANA, I. P; EUGÊNIO, B. G. (Orgs) Estágio Supervisionado, Formação e Desenvolvimento Profissional Docente. São Carlos, SP: Pedro\&João Editores. 2012.

O Ensino por Meio da Pesquisa: O projeto "Ciência na Escola". Tese de doutorado. Campinas, SP: UNICAMP. 2002.

GALLO, S. Deleuze e a Educação. Coleção Pensadores e Educação. Belo Horizonte: Autêntica. 2008.

LUSTOSA, F. G. Inclusão, o olhar que ensina: o movimento da mudança e a transformação das práticas pedagógicas no contexto de uma pesquisa-ação colaborativa. Doutorado (Tese em Educação). Fortaleza: Universidade Federal do Ceará. 2009.

.; SANTOS. J.A.S. O que se ensina e se aprende na escola fundamental com os ritos de instituição: práticas de dominação, disciplina e conflitos. XIX EPENN - Encontro de Pesquisa Educacional do Norte e Nordeste. João Pessoa: 2010.

Olh@res, Guarulhos, v. 1, n1, p. 90-115, maio. 2013. 
NÓVOA, A. (Org.). Vidas de professores. 2. ed. Portugal: Porto, 1992.

PERRENOUD, P. Pedagogia diferenciada: das intenções a ação. Trad. Patricia Chittoni Ramos. Porto Alegre: Artes Médicas Sul, 2000.

PIMENTA, S. G; LIMA, M. S. L. Estágio e Docência. São Paulo: Cortez. 2004.

SACRISTÁN, J. G. Consciência e Acção Sobre a Prática Como Libertação Profissional dos Professores. In: NÓVOA, A (Org.) Profissão Professor. Colecção Ciências da Educação. Porto, Portugal: Porto Editora, 1995.

SCHÖN, D. A. Formar professores como profissionais reflexivos. In. NÓVOA, A. (Org.). O professor e sua formação. Lisboa: D. Quixote, 1992.

TARDIF, M. Saberes docentes e formação profissional. Petrópolis, RJ: Vozes, 2002.

ZABALlA, A. A prática educativa: como ensinar. Trad: Ernani F. da F. Rosa. Porto Alegre: Artmed. 1998. 